\title{
ENERGY OPTIMIZATION STUDY IN AN ETHANOL PRODUCTION UNIT USING PINCH TECHNOLOGY
}

\author{
Yan Costa das Neves ${ }^{1}$ and Savio de Siqueira Magalhães ${ }^{1}$
}

${ }^{1}$ Affiliation not available

October 15,2020

\begin{abstract}
This work presents an energy optimization study in a distillation and dehydration unit of a conventional ethanol producing biorefinery, based on the Pinch method. This proposal resulted in savings of $69.2 \%$ in operational costs with utilities, just with energy integration, turning the process significantly cheaper.
\end{abstract}

\section{Hosted file}

ENERGY OPTIMIZATION STUDY .pdf available at https://authorea.com/users/367505/articles/ 486897-energy-optimization-study-in-an-ethanol-production-unit-using-pinch-technology

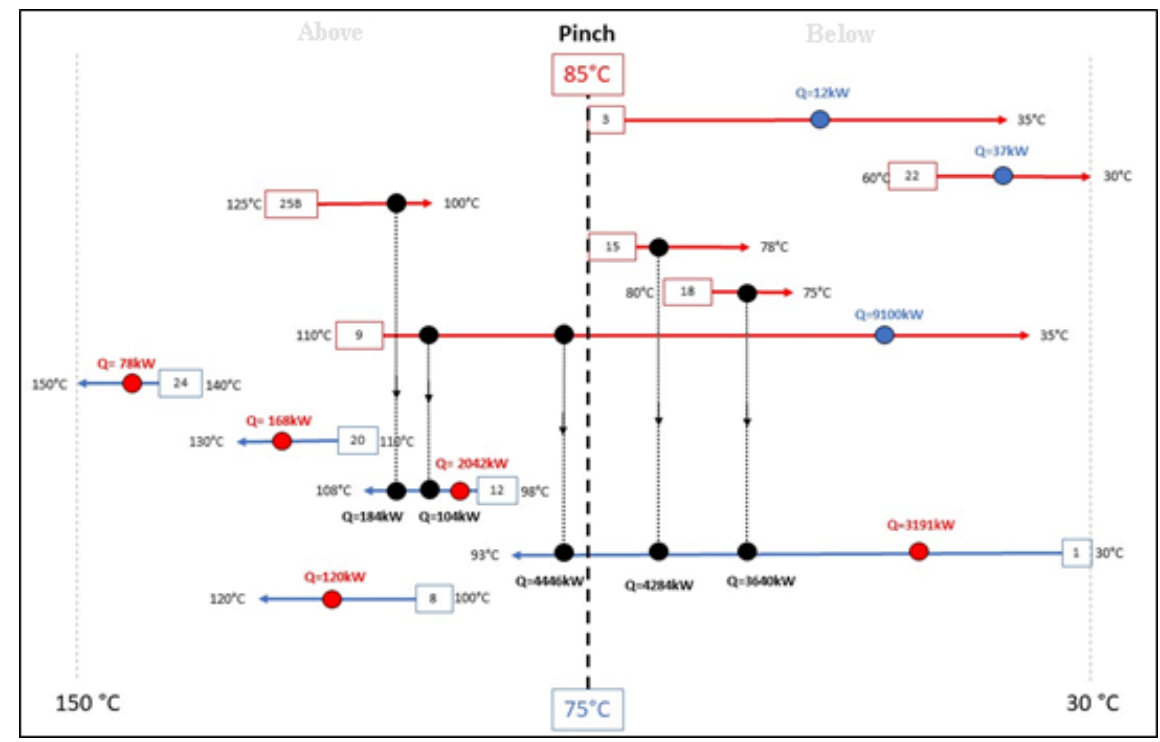

